TITLE:

\title{
Effect of particle shape on powder flowability of microcrystalline cellulose as determined using the vibration shear tube method.
}

\section{$\operatorname{AUTHOR(S):~}$}

Horio, Takehiko; Yasuda, Masatoshi; Matsusaka, Shuji

\section{CITATION:}

Horio, Takehiko ...[et al]. Effect of particle shape on powder flowability of microcrystalline cellulose as determined using the vibration shear tube method.. International journal of pharmaceutics 2014, 473(1-2): 572-578

ISSUE DATE:

2014-10-01

URL:

http://hdl.handle.net/2433/189549

\section{RIGHT:}

(c) 2014 Elsevier B.V.; この論文は出版社版でありません。引用の際には 出版社版をご確認ご利用ください。; This is not the published version. Please cite only the published version. 


\section{Original Paper for International Journal of Pharmaceutics}

Effect of particle shape on powder flowability of microcrystalline cellulose as determined using the vibration shear tube method

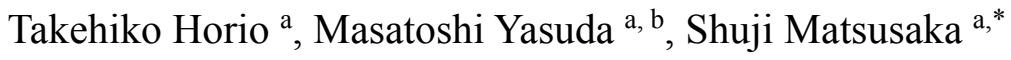

${ }^{a}$ Department of Chemical Engineering, Kyoto University, Kyoto 615-8510, Japan

${ }^{\mathrm{b}}$ IMP, 67-20 Ichibu-cho, Ikoma-shi, Nara 630-0222, Japan

* Corresponding author at: Department of Chemical Engineering, Kyoto University, Kyoto 615-8510, Japan. Tel.: +81 75383 3054; Fax: +81 753833054 .

E-mail address: matsu@cheme.kyoto-u.ac.jp (S. Matsusaka).

Keywords:

Flowability

Microcrystalline cellulose

Particle shape

Aspect ratio

Lubrication

Vibration shear tube method 


\section{Abstract}

Powder flowability of microcrystalline cellulose particles having different particle shapes, whose aspect ratios ranged from 1.8 to 6.4 , was measured using the vibration shear tube method. Particles lubricated with magnesium stearate were also investigated in order to evaluate the effect of surface modification on powder flowability. Particles were discharged through a narrow gap between a vibrating tube edge and a flat bottom surface, where each particle experienced high shear forces, thus, overcoming adhesion and friction forces. Vibration amplitude was increased at a constant rate during measurement and the masses of the discharged particles were measured at consistent time intervals. Flowability profiles, i.e., the relationships between the mass flow rates of the discharged particles and their vibration accelerations, were obtained from these measurements. Critical vibration accelerations and characteristic mass flow rates were then determined from flowability profiles in order to evaluate static and dynamic friction properties. The results were compared with those obtained using conventional methods. It was found that angle of repose and compressibility were related to static and dynamic friction properties. Furthermore, it was found that particle aspect ratio more significantly affects powder flowability than does lubrication with magnesium stearate. 


\section{Introduction}

Microcrystalline cellulose (MCC) is widely used in the pharmaceutical industry because of its excellent compressibility (York et al., 1990; Doelker et al., 1993, 1995; Hancock et al., 2000; Inman et al., 2008). One of the reasons for its widespread use is that MCC can perform diverse functions; applicability for a particular function is determined by the shape and internal structure of the MCC particles (Obae et al., 1999). In pharmaceutical manufacturing processes, appropriate excipients must be selected by considering such factors as tablet hardness, disintegration time, dissolution profile, and powder flowability. Furthermore, to improve medication compliance and persistence, formulations with appropriately sized tablets must be designed. To make smaller tablets and capsules, smaller quantities of more highly-functional excipients must be used in formulations.

In recent years, several grades of highly-functional MCC have been developed. For example, spherical MCC particles with a porous structure exhibit higher compressibility and improved powder flowability. On the other hand, elongated fibrous MCC, in a tight packing state, has been developed to increase tablet hardness. The effect of particle shape on powder flowability was studied by Ridgway and Rupp (1969), Podczeck and Miah (1996), Fu et al. (2012), and Mellmann et al. (2013). Evaluation of the flowability of fibrous MCC has been carried out by measuring its angle of repose, and/or compressibility (Landín et al., 1993; Patel and Podczeck, 1996; Mohammadi and Harnby, 1997; Gamble et al., 2011). However, measurements of angles of repose of cohesive and fibrous powders are not easy (Wouters and Geldart, 1996; Schulze, 2008; Krantz et al., 2009). Powder flowability can also be measured by other methods (Schwedes, 2003; Lumay et al., 2012), e.g. using a shear cell (Jenike, 1962; Antequera 
et al., 1994; Shi et al., 2011; Yu, 2011; Nalluri et al., 2013), rotary rheometer (Freeman et al., 2007, 2009), and revolutionary drum (Lavoie et al., 2002; Bhattachar et al., 2004; Hancock et al., 2004), or by employing Carr's method (Carr, 1965a,b). However, these methods require large amounts of sample powder and significant technical knowledge and skill. Hassanpour and Ghadiri (2007); Wang et al. (2008) developed the ball indentation method, enabling the evaluation of powder flowability of small samples. Jiang et al. $(2006,2009)$ invented the vibrating tube method for evaluating powder flowability, which is inspired from the micro-feeding of fine powders (Matsusaka et al., 1995, 1996). The method enables high-sensitivity measurement of powder flowability of small samples and the evaluation of both static and dynamic friction properties of various powders (Ishii et al., 2009, 2011a,b). Applying the vibrating tube method, Horio et al. (2013) evaluated the powder flowability of pharmaceutical powders. However, this method cannot be used for the evaluation of extremely cohesive powders or fibrous powders that do not flow through the narrow tube.

Zainuddin et al. (2012a,b) have developed the vibration shear tube method to evaluate static and dynamic friction properties of nanoparticles and micron-sized particles. This method measures the mass flow rate of particles discharged through a narrow gap between a vibrating tube edge and a flat bottom surface, where each particle experiences high shear forces, thus, overcoming adhesion and friction forces. However, comparisons of results obtained from the vibration shear tube method and those of conventional methods have not been performed.

In the present study, the powder flowability of MCC particles having different particle shapes is evaluated using the vibration shear tube method. From the 
perspective of static and dynamic friction properties, the results obtained using conventional methods, i.e., angle of repose and compressibility, are analyzed. Furthermore, the effects of particle aspect ratio and lubrication with magnesium stearate $(\mathrm{MgSt})$ on powder flowability are investigated.

\section{Materials}

\subsection{Sample preparation}

Different types of Ceolus ${ }^{\circledR}$ MCC particles, PH-101, PH-102, PH-200, PH-301, PH-302, UF-702, KG-802, and KG-1000 (Asahi Kasei Chemicals Corporation, Japan) were used. Scanning electron microscopy (SEM) images of the MCC particles are shown in Fig. 1. PH-101 was a powder consisting of both fibrous and elongated particles. The particles of $\mathrm{PH}-102$ had a longer minor axis, width, than those of PH-101. Some particles of PH-200 were over $200 \mu \mathrm{m}$. The particle size of PH-301 was similar to that of $\mathrm{PH}-101$; however, the major axis lengths of $\mathrm{PH}-301$ particles were smaller than those of PH-101 particles. PH-302 had larger particles than PH-301. UF-702 had elongated particles compared to PH-302. KG-802 had even more elongated particles and KG-1000 had the most elongated particles.

Fig. 2 shows the cumulative distribution functions, $F$, of the major axis lengths, $L$, of the MCC particles. More than 200 values for each sample were measured by SEM image analysis. The particle lengths of PH-301 were short, with a median value of approximately $50 \mu \mathrm{m}$. The median values of the particle lengths of KG-802 and KG-1000 were both approximately $100 \mu \mathrm{m}$. The median value of the particle lengths of PH-200 was as large as $120 \mu \mathrm{m}$. Table 1 summarizes the powder properties, including nominal mass median diameter, median value of major axis length, minor axis 
length, width, and aspect ratio, $A_{r}$, i.e., ratio of the major axis to the minor axis. The values of nominal mass median diameter can be classified into three categories corresponding to 50,90 , and $170 \mu \mathrm{m}$. The maximum value of the aspect ratio was 6.4 , for KG-1000, and the second highest value was 3.6, for KG-802. The particles of the other samples all had an aspect ratio of approximately 2 . In the pharmaceutical industry, MCC particles with aspect ratios of approximately 2 are often used for direct compression excipients because of their superior flowability. MCC particles with higher aspect ratios are used, in a tight packing state, to increase tablet hardness. In general, such MCC particles are lubricated with MgSt before tableting; however, the effect of lubrication of MCC particles having different particle shapes on powder flowability is still unclear. In this experiment, 0.5 mass \% of $\mathrm{MgSt}$ that was sieved through a $500-\mu \mathrm{m}$ mesh was added to MCC particles. The MCC and MgSt were mixed in a tumbling blender (Bohle Bin blender LM-20; Kotobuki Industries Co., Ltd., Japan) at $20 \mathrm{rpm}$ for 5 minutes. The effective volume of the blender is between $25-85 \%$ of the total container volume. The container had a volume of $2.5 \mathrm{~L}$ and was filled with the mixture to $50 \%$ capacity. The sample preparation and flowability measurements were performed at a temperature of $21 \pm 2{ }^{\circ} \mathrm{C}$ and relative humidity of $45 \pm 5 \%$.

\subsection{Angle of repose and compressibility}

Angle of repose, $\theta$, was measured using a device (ABD-72, Tsutsui Scientific Instruments Co., Ltd., Japan). Bulk density, tapped density, and compressibility were obtained using another device (KYT-4000, Seishin Enterprise Co., Ltd., Japan). All the measurements were repeated 3 times for each sample. MCC particles $\left(W_{p}=12 \mathrm{~g}\right.$ 
for KG-1000, $W_{p}=15 \mathrm{~g}$ for other types of powder) were placed into a 100 -ml cylinder and the volumes of piled powders, $V_{b}(\mathrm{~mL})$, were measured. Bulk density, $\rho_{b}(\mathrm{~g} / \mathrm{mL})$, was calculated using the following equation.

$$
\rho_{b}=W_{p} / V_{b}
$$

Tapped density, $\rho_{t}(\mathrm{~g} / \mathrm{mL})$, was calculated from the volume of a packed powder, $V_{t}(\mathrm{~mL})$, after 180 taps. Compressibility, $C(\%)$, was calculated using the following equation.

$$
C=100 \times\left(\rho_{t}-\rho_{b}\right) / \rho_{t}
$$

The results for angle of repose, bulk density, tapped density, and compressibility are shown in Table 1. According to Carr's index (Carr, 1965a,b), powder flowability based on angle of repose is good from $31-35^{\circ}$; fair from $36-40^{\circ}$; passable from $41-45^{\circ}$; poor from $46-55^{\circ}$; and very poor from $56-65^{\circ}$. Powder flowability based on compressibility is fair from 16-20\%; passable from $21-25 \%$; poor from $26-31 \%$; very poor from $32-37 \%$; and extremely poor when $\geq 38 \%$. Namely, high values indicate poor flowability.

The maximum value of angle of repose presented in Table 1 is $58^{\circ}$, corresponding to $\mathrm{KG}-1000$, and the second highest is $49^{\circ}$, corresponding to KG-802. The flowability of these powders is, therefore, considered very poor and poor, respectively. The minimum value of the angle of repose presented in Table 1 is $36^{\circ}$, corresponding to PH-200, indicating fair flowability. The maximum value of compressibility indicated in Table 1 is $45 \%$, corresponding to KG-1000, and the second highest is $36 \%$, corresponding to KG-802. The flowability of these powders is, therefore, considered extremely poor and very poor, respectively. The minimum value presented in Table 1 is $21 \%$, corresponding to $\mathrm{PH}-200$, which, therefore, is considered to have passable flowability. When particles are small and fibrous, powder flowability is poor. 


\section{Experimental apparatus and procedure}

To evaluate powder flowability, we used the vibration shear tube method developed by Zainuddin et al. (2012a, b). Fig. 3 shows a schematic diagram of the experimental setup based on a dynamic powder flow tester (DPFS-01, IMP Co., Ltd., Japan). This system consists of a glass tube, a bottom, a piezoelectric vibrator, a laser vibrometer, a digital balance, and a computer. The glass tube, $200 \mathrm{~mm}$ long, $8 \mathrm{~mm}$ in inner diameter, $10 \mathrm{~mm}$ in outer diameter, was held vertically, and the bottom, with a diameter of $10 \mathrm{~mm}$, was placed below the tube with a narrow gap. The gap distance is the width of the outlet slit for powder discharge. In general, fine particles tend to agglomerate and block the passage. For a narrow gap, high vibration is required to flow through the gap; while for a wide gap, high vibration is not needed. When high sensitive measurement is needed to distinguish small differences between powders with similar flowability, the gap distance should be decreased though high vibration acceleration is required (Zainuddin et al., 2012b). In this experiment, the gap distance was set to 0.8 $\mathrm{mm}$. The piezoelectric vibrator was fixed to the tube at a height of $50 \mathrm{~mm}$ from the bottom end of the tube. Relative movement in the gap occurred due to horizontal vibration of the tube. The vibration amplitude was measured at a height of $10 \mathrm{~mm}$ from the bottom edge using a laser vibrometer, and controlled by a feedback system. In order to evaluate both static and dynamic friction properties, the amplitude needs to be changed. The vibration amplitude was increased at a constant rate of $1 \mu \mathrm{m} / \mathrm{s}$ up to $100 \mu \mathrm{m}$; thus, the measurement time was $100 \mathrm{~s}$. The vibration acceleration, $\alpha$, was calculated using the following equation.

$$
\alpha=A(2 \pi f)^{2}
$$


where $A$ is the vibration amplitude and $f$ is the frequency. In this system, the frequency was fixed at $280 \mathrm{~Hz}$ so as to maximize vibration amplitude due to resonance. Therefore, the increasing rate of vibration acceleration, $\mathrm{d} \alpha / \mathrm{d} t$, was $3.1 \mathrm{~m} / \mathrm{s}^{3}$, and the maximum vibration acceleration was $310 \mathrm{~m} / \mathrm{s}^{2}$. A digital balance with a resolution of $0.1 \mathrm{mg}$ and a response time of $1 \mathrm{~s}$ was used to measure the mass of particles discharged. The data was recorded in the computer at $2 \mathrm{~s}$ intervals. Powder was placed into the tube using a removable funnel, and a pretest under vibration was carried out to fill it uniformly; the measurement was repeated 10 times under the same conditions. When the vibration acceleration (or the vibration amplitude) exceeds a certain value, particles in the tube begin to flow out of the outlet slit and fall on the digital balance due to gravity. The mass of the discharged particles increases with time. The mass flow rate of the particles was automatically calculated from the variation of the mass per unit time, and the relationship between the mass flow rate and the vibration acceleration (i.e., flowability profile) was obtained.

\section{Results and Discussion}

\subsection{Flowability profiles}

Fig. 4 shows the flowability profiles, i.e., the relationships between the mass flow rates, $w$, of discharged particles and their vibration accelerations, for the different types of MCC particles. Although the flowability profiles depend on the type of MCC particles, they show common features. Particles begin to flow through the gap between the edge of the glass tube and the bottom surface after exceeding the critical vibration acceleration, which is related to static friction property. On the other hand, the mass flow rates of particles depend on dynamic friction property. The critical 
vibration acceleration, $\alpha_{c}$, was determined by the minimum vibration acceleration where the mass flow rate exceeded a constant value of $2 \mathrm{mg} / \mathrm{s}$ (Zainuddin et al., 2012a, b). To evaluate dynamic friction property, characteristic mass flow rates, $w_{\alpha}$, were determined from mass flow rates using a constant vibration acceleration of $300 \mathrm{~m} / \mathrm{s}^{2}$ (Zainuddin et al., 2012a, b). Table 2 shows the values of critical vibration acceleration and characteristic mass flow rate. These characteristic values are discussed in later sections.

4.2. Relationship between characteristic values obtained using the vibration shear tube method and angle of repose

Fig. 5 shows the relationship between the critical vibration acceleration and the angle of repose of different types of MCC particles. The critical vibration acceleration increases with increasing angle of repose. The coefficient of determination, $R^{2}$, for this dependence was found to be 0.77 . When static friction force is larger, critical vibration acceleration is higher; therefore, the angle of repose is correlated to static friction property. For example, the values for KG-1000 $\left(\theta=58^{\circ}, \alpha_{c}=109 \mathrm{~m} / \mathrm{s}^{2}\right)$ and KG-802 $\left(\theta=49^{\circ}, \alpha_{c}=82 \mathrm{~m} / \mathrm{s}^{2}\right)$ indicate that KG-1000 experiences higher static friction forces. Elongated particle shape is thought to increase the strength of interactions between particles. For powders with poor flowability, it is difficult to accurately measure angles of repose because of the irregular and non-linear slopes of piles of such powders; however, using the vibration shear tube method, a quantitative measurement of powder flowability can be easily obtained irrespective of particle size and shape.

Fig. 6 shows the relationship between the characteristic mass flow rate and the angle of repose. As the angle of repose increases, the characteristic mass flow rate related to 
dynamic friction property decreases. The coefficient of determination for this relationship was found to be 0.76 . Thus, dynamic friction property has also been correlated to angle of repose. In general, the angle of repose of a powder is thought to be related to static friction property; however, our results show that angle of repose depends on both dynamic friction property as well as static friction property. This can be explained by the fact that the powder piles are formed under avalanche conditions.

4.3. Relationship between characteristic values obtained using the vibration shear tube method and compressibility

Fig. 7 shows the relationship between the critical vibration acceleration and the compressibility. The critical vibration acceleration increases with increasing compressibility. The coefficient of determination for this relationship was found to be 0.81, which was rather high. Fig. 8 shows the relationship between the characteristic mass flow rate and the compressibility. The characteristic mass flow rate decreases with increasing compressibility. The coefficient of determination for this relationship was found to be 0.66. Comparison of the coefficients of determination shown in Figs. 7 and 8 implies that compressibility depends more on static friction property than dynamic friction property.

4.4. Effects of particle aspect ratio and surface modification of particles on powder flowability

Samples of pure MCC particles and samples of particles lubricated with 0.5 mass $\%$ of $\mathrm{MgSt}$ were used to investigate the effects of particle aspect ratio and surface modification on powder flowability. The values of particle aspect ratio ranged from 
2.0 to 6.4. Experimental results for critical vibration acceleration and characteristic mass flow rate are summarized in Table 2. To reduce the effect of particle size on powder flowability, results for powders with the same mass median diameter must be compared with each other.

Fig. 9 shows the effects of particle aspect ratio and surface modification on the critical vibration acceleration through data obtained from unlubricated and lubricated particles, where $D_{p 50}=50 \mu \mathrm{m}$. Critical vibration acceleration tends to increase with increasing particle aspect ratio. This indicates that particle aspect ratio affects static friction forces. However, when particle aspect ratio is varied from 2 to 4, for unlubricated particles, the effect on critical vibration acceleration is small. Conversely, for lubricated particles, the effect is prominent and it was found that flowability related to static friction property improved for lower aspect ratios when MgSt was used. This result was consistent with a widely accepted concept that powder flowability can be improved by lubricating with MgSt. However, flowability related to static friction property was not improved for higher aspect ratio. As the particles had lower bulk density, the intensity of shear in the blender might be too weak to disperse MgSt.

Fig. 10 shows the effects of particle aspect ratio and surface modification on the characteristic mass flow rate. The values of the characteristic mass flow rate are larger at lower aspect ratios and reduced at higher aspect ratios. This result indicates that higher aspect ratios result in higher dynamic friction forces. Furthermore, it was found that characteristic mass flow rate decreased when lubrication was performed, i.e., lubricating with MgSt did not effectively reduce the dynamic friction forces between fibrous particles. This might be the result of non-uniform dispersion of the MgSt lubricant amidst the fibrous particles; in other words, lubricant agglomeration might 
adversely affect dynamic friction property. Therefore, a widely accepted concept that powder flowabiltiy is improved by lubricating with $\mathrm{MgSt}$ seems to be related to static friction property. It was reported that high-shear mixing of spray-dried lactose and MgSt effectively increased average mass flow rates related to dynamic friction forces, while low-shear mixing in a tumbling blender did not improve the average mass flow rate even though blending time was extended up to 60 minutes (Horio et al., 2013). This means that dynamic friction property is hardly improved in the tumbling blender. Sudah et al. (2002) also reported that cohesive mixtures seem to be rather insensitive to mixing time. MgSt dispersion generally depends on fill level, blender size, blending speed, and blending time (Duong et al., 2003; Arratia et al., 2006; Kushner and Moore, 2010). In order to improve both static and dynamic friction properties of fibrous MCC particles with MgSt, the effects of various blending conditions need to be examined. This is a subject for future research.

\section{Summary and conclusion}

In the present study, the flowability of MCC particles having different particle shapes was measured using the vibration shear tube method. From experimental results, characteristic values related to static and dynamic friction properties were obtained and compared with results obtained using conventional methods, and angle of repose and compressibility were analyzed with respect to static and dynamic friction properties. Furthermore, the effects of particle aspect ratio and lubrication with MgSt on powder flowability were investigated. The results obtained are summarized as follows:

(1) The vibration shear tube method can detect differences in powder flowability of MCC particles having different particle shapes and be used to evaluate their static 
and dynamic friction properties.

(2) Angle of repose increases with increasing critical vibration acceleration and decreasing mass flow rate; i.e., angle of repose is correlated to static and dynamic friction properties.

(3) Compressibility shows a similar tendency to angle of repose; however, the effect of static friction property on compressibility is more significant than that of dynamic friction property.

(4) As particle aspect ratio increases, critical vibration acceleration increases and characteristic mass flow rate decreases. These results indicate that higher aspect ratios result in higher static and dynamic friction forces.

(5) Lubricating with MgSt can reduce static friction forces in powders composed of particles with lower aspect ratios, but it is ineffective for reducing dynamic friction forces. 


\section{References}

Arratia P.E., Duong N.-H., Muzzio F.J., Godbole P., Lange A., Reynolds S., 2006. Characterizing mixing and lubrication in the Bohle Bin blender. Powder Technol., 161, 202-208.

Antequera M.V.V., Ruiz A.M., Perales M.C.M., Muñoz N.M., Ballesteros M.R.J.C., 1994. Evaluation of an adequate method of estimating flowability according to powder characteristics. Int. J. Pharm. 103, 155-161.

Bhattachar S.N., Hedden D.B., Olsofsky A.M., Qu X., Hsieh W.Y., Canter K.G., 2004. Evaluation of the vibratory feeder method for assessment of powder flow properties. Int. J. Pharm. 269, 385-392.

Carr R.L., 1965a. Evaluating flow properties of solids. Chem. Eng. January 18, $163-168$.

Carr R.L., 1965b. Classifying flow properties of solids. Chem. Eng. February 1, 69-72.

Doelker E., 1993. Comparative compaction properties of various microcrystalline cellulose types and generic products. Drug Dev. Ind. Pharm., 19, 2399-2471.

Doelker E., Massuelle D., Veuillez F., Humbert-Droz P., 1995. Morphological, packing, flow and tableting properties of new avicel types. Drug Dev. Ind. Pharm., 21, 643-661.

Duong N.-H., Arratia P., Muzzio F., Lange A., Timmermans J., Reynolds S., 2003. A homogeneity study using NIR spectroscopy: Tracking magnesium stearate in Bohle bin-blender. Drug Dev. Ind. Pharm., 29, 679-687.

Freeman R., 2007. Measuring the flow properties of consolidated, conditioned and aerated powders - A comparative study using a powder rheometer and a rotational shear cell. Powder Technol., 174, 25-33.

Freeman R.E., Cooke J.R., Schneider L.C.R., 2009. Measuring shear properties and 
normal stresses generated within a rotational shear cell for consolidated and non-consolidated powders. Powder Technol. 190, 65-69.

Fu X., Huck D., Makein L., Armstrong B., Willen U., Freeman T., 2012. Effect of particle shape and size on flow properties of lactose powders. Particuology, 10, 203-208.

Gamble J.F., Chiu W.S., Tobyn M., 2011. Investigation into the impact of sub-populations of agglomerates on the particle size distribution and flow properties of conventional microcrystalline cellulose grades. Pharm. Dev. Technol., 16, 542-548.

Hancock B.C., Clas S.D., Christensen K., 2000. Micro-scale measurement of the mechanical properties of compressed pharmaceutical powders. 1: The elasticity and fracture behavior of microcrystalline cellulose. Int. J. Pharm., 209, 27-35.

Hancock B.C., Vukovinsky K.E., Brolley B., Grimsey I., Hedden D., Olsofsky A., Doherty R.A., 2004. Development of a robust procedure for assessing powder flow using a commercial avalanche testing instrument. J Pharm. Bio. Anal. 35, 979-990. Hassanpour A., Ghadiri M., 2007. Characterisation of flowability of loosely compacted cohesive powders by Indentation. Part. Part. Syst. Charact. 24, 117-123.

Horio T., Yasuda M., Matsusaka S., 2013. Measurement of flowability of lubricated powders by the vibrating tube method. Drug Dev. Ind. Pharm. 39, 1063-1069.

Inman S.J., Briscoe B.J., Pitt K.G., Shiu C., 2008. Axial tensile fracture of microcrystalline cellulose compacts. Int. J. Pharm. 349, 172-179.

Ishii K., Suzuki M., Yamamoto T., Kihara Y., Kato Y., Kurita T., Yoshimoto K., Yasuda M., Matsusaka S., 2009. Flowability measurement of coarse particles using vibrating tube method. J. Chem. Eng. Jpn. 42, 319-324. 
Ishii K., Suzuki M, Segawa T., Kihara Y., Yasuda M., Matsusaka S., 2011a. Flowability measurement of pulverized and granulated materials using vibrating tube method. Adv. Powder Technol. 22, 319-323.

Ishii K., Suzuki M., Segawa T., Kihara Y., Yasuda M., Matsusaka S., 2011b; A vibrating tube method for evaluating flowability of a small amount of sample particles. Adv. Powder Technol., 22, 522-525.

Jenike A.W., 1962. Gravity flow of solids. Trans. Instn. Chem. Engrs. 40, 264-271.

Jiang Y, Matsusaka S, Masuda H, Yokoyama T., 2006. Evaluation of flowability of composite particles and powder mixtures by a vibrating capillary method. J. Chem. Eng. Jpn, 39, 14-21.

Jiang Y, Matsusaka S, Masuda H, Qian Y., 2009. Development of measurement system for powder flowability based on vibrating capillary method. Powder Technol., 188, $242-247$.

Krantz M., Zhang H., Zhu J., 2009. Characterization of powder flow: Static and dynamic testing. Powder Technol. 194, 239-245.

Kushner IV J., Moore F., 2010. Scale-up model describing the impact of lubrication on tablet tensile strength. Int. J. Pharm. 399, 19-30.

Landín M., Martínez-Pacheco R., Gómez-Amoza J.L., Souto C., Concheiro A., Rowe R.C., 1993. Effect of country of origin on the properties of microcrystalline cellulose. Int. J. Pharm. 91, 123-131.

Lavoie F, Cartilier L., Thibert R., 2002. New methods characterizing avalanche behavior to determine powder flow. Pharm. Res., 19, 887-893.

Lumay G., Boschini F., Traina K., Bontempi S., Remy J.C., Cloots R., Vandewalle N., 2012. Measuring the flowing properties of powders and grains. Powder Technol., 224, 
$19-27$.

Matsusaka S, Urakawa M, Masuda H., 1995. Micro-feeding of fine powders using a capillary tube with ultrasonic vibration. Adv. Powder Technol., 6, 283-293.

Matsusaka S, Yamamoto K, Masuda H., 1996. Micro-feeding of a fine powders using a vibrating capillary tube. Adv. Powder Technol., 7, 141-151.

Mellmann J., Hoffmann T., Fürll C., 2013. Flow properties of crushed grains as a function of the particle shape. Powder Technol. 249, 269-273.

Mohammadi M.S., Harnby N., 1997. Bulk density modelling as a means of typifying the microstructure and flow characteristics of cohesive powders, Powder Technol. 92, $1-8$.

Nalluri V.R., Puchkov M., Kuentz M., 2013. Toward better understanding of powder avalanching and shear cell parameters of drug-excipient blends to design minimal weight variability into pharmaceutical capsules. Int. J. Pharm. 442, 49-56.

Obae, K., Iijima H., Imada K., 1999. Morphological effect of microcrystalline cellulose particles on tablet tensile strength. Int. J. Pharm, 182, 155-164.

Sudah O.S., Arratia P.E., Coffin-Beach D., Muzzio F.J., 2002. Mixing of cohesive pharmaceutical formulations in Tote (Bin) blenders. Drug Dev. Ind. Pharm., 28, 905-918.

Patel R., Podczeck F., 1996. Investigation of the effect of type and source of microcrystalline cellulose on capsule filling. Int. J. Pharm. 128, 123-127.

Podczeck F., Miah Y., 1996. The influence of particle size and shape on the angle of internal friction and the flow factor of unlubricated and lubricated powders. Int. J. Pharm. 144, 187-194.

Ridgway K., Rupp R., 1969. The effect of particle shape on powder properties. J. Pharm. 
Pharmacol. 21, Suppl., 30S-39S.

Schulze D., 2008. Powders and Bulk Solids: Behavior, Characterization, Storage and Flow., Springer, New York.

Schwedes J., 2003. Review on testers for measuring flow properties of bulk solids. Granular Matter 5, 1-43.

Shi L., Chattoraj S., Sun C.C., 2011. Reproducibility of flow properties of microcrystalline cellulose - Avicel PH102. Powder Technol. 212, 253-257.

York P., Bassam F., Rowe R.C., Roberts R.J., 1990. Fracture mechanics of microcrystalline cellulose powders. Int. J. Pharm. 66, 143-148.

Yu W., Muteki K., Zhang L., Kim G., 2011. Prediction of bulk powder flow performance using comprehensive particle size and particle shape distributions. J. Pharm. Sci. 100, 284-293.

Wang C., Hassanpour A., Ghadiri M., 2008. Characterisation of flowability of cohesive powders by testing small quantities of weak compacts. Particuology. 6, 282-285.

Wouters I.M.F., Geldart D., 1996. Characterising semi-cohesive powders using angle of repose. Par. Par. Syst. Charact., 13, 254-259.

Zainuddin I.M., Yasuda M., Horio T., Matsusaka S., 2012a. Experimental study on powder flowability using vibration shear tube method. Par. Par. Syst. Charact., 29, 8-15. Zainuddin M.I., Yasuda M., Liu Y.-H., Maruyama H., Matsusaka S., $2012 b$. Development of vibration shear tube method for powder flowability evaluation, Powder Technol., 217, 548-553. 
Table 1: Powder properties of microcrystalline cellulose.

\begin{tabular}{ccccccccc}
\hline Sample number & $\begin{array}{c}D_{p 50} *^{*} \\
(\mu \mathrm{m})\end{array}$ & $\begin{array}{c}\text { Length** } \\
(\mu \mathrm{m})\end{array}$ & $\begin{array}{c}\text { Width** } \\
(\mu \mathrm{m})\end{array}$ & $\begin{array}{c}\text { Aspect } \\
\text { ratio** } \\
(-)\end{array}$ & $\begin{array}{c}\text { Angle of } \\
\text { repose } \\
\left({ }^{\circ}\right)\end{array}$ & $\begin{array}{c}\text { Bulk } \\
\text { density } \\
(\mathrm{g} / \mathrm{mL})\end{array}$ & $\begin{array}{c}\text { Tapped } \\
\text { density } \\
(\mathrm{g} / \mathrm{mL})\end{array}$ & $\begin{array}{c}\text { Compress- } \\
\text { ibility } \\
(\%)\end{array}$ \\
\hline PH-101 & 50 & 71 & 28 & 2.3 & 45 & 0.31 & 0.44 & 30 \\
PH-102 & 90 & 75 & 33 & 2.1 & 40 & 0.32 & 0.43 & 26 \\
PH-200 & 170 & 123 & 62 & 1.8 & 36 & 0.35 & 0.44 & 21 \\
PH-301 & 50 & 52 & 23 & 2.0 & 39 & 0.39 & 0.54 & 28 \\
PH-302 & 90 & 81 & 41 & 1.9 & 41 & 0.41 & 0.54 & 24 \\
UF-702 & 90 & 81 & 35 & 2.1 & 42 & 0.29 & 0.39 & 26 \\
KG-802 & 50 & 97 & 25 & 3.6 & 49 & 0.24 & 0.37 & 36 \\
KG-1000 & 50 & 96 & 16 & 6.4 & 58 & 0.14 & 0.25 & 45 \\
\hline
\end{tabular}

* nominal mass median diameter.

** median value for each quantity

Table 2: Values of critical vibration acceleration and characteristic mass flow rate (mean and standard deviation of 10 measurements).

\begin{tabular}{ccccc}
\hline \multirow{2}{*}{ Sample number } & \multicolumn{2}{c}{ Unlubricated powders } & \multicolumn{2}{c}{ MgSt lubricated powders } \\
\cline { 2 - 5 } & $\begin{array}{c}\text { Critical vibration } \\
\text { acceleration }\left(\mathrm{m} / \mathrm{s}^{2}\right)\end{array}$ & $\begin{array}{c}\text { Characteristic mass } \\
\text { flow rate }(\mathrm{mg} / \mathrm{s})\end{array}$ & $\begin{array}{c}\text { Critical vibration } \\
\text { acceleration }\left(\mathrm{m} / \mathrm{s}^{2}\right)\end{array}$ & $\begin{array}{c}\text { Characteristic mass } \\
\text { flow rate }(\mathrm{mg} / \mathrm{s})\end{array}$ \\
\hline PH-101 & $88 \pm 6$ & $69 \pm 2$ & $71 \pm 6$ & $47 \pm 5$ \\
PH-102 & $76 \pm 6$ & $70 \pm 2$ & - & - \\
PH-200 & $57 \pm 2$ & $73 \pm 3$ & - & - \\
PH-301 & $80 \pm 4$ & $85 \pm 6$ & $72 \pm 2$ & $70 \pm 5$ \\
PH-302 & $66 \pm 3$ & $79 \pm 4$ & - & - \\
UF-702 & $82 \pm 6$ & $50 \pm 1$ & - & - \\
KG-802 & $82 \pm 5$ & $49 \pm 3$ & $88 \pm 6$ & $40 \pm 3$ \\
KG-1000 & $109 \pm 10$ & $24 \pm 2$ & $120 \pm 9$ & $20 \pm 5$ \\
\hline
\end{tabular}




\section{List of Figures}

Fig. 1. SEM images of the different types of MCC particles.

Fig. 2. Cumulative distribution functions, $F$, of the major axis lengths, $L$, of the MCC particles.

Fig. 3. Schematic diagram of the experimental setup.

Fig. 4. Flowability profiles obtained using the vibration shear tube method.

Fig. 5. Relationship between critical vibration acceleration, $\alpha_{c}$, and angle of repose, $\theta$.

Fig. 6. Relationship between characteristic mass flow rate, $w_{\alpha}$, and angle of repose, $\theta$.

Fig. 7. Relationship between critical vibration acceleration, $\alpha_{c}$, and compressibility, $C$.

Fig. 8. Relationship between characteristic mass flow rate, $w_{\alpha}$, and compressibility, $C$.

Fig. 9. Effects of particle aspect ratio, $A_{r}$, and surface modification on critical vibration acceleration, $\alpha_{c}$.

Fig. 10. Effects of particle aspect ratio, $A_{r}$, and surface modification on characteristic mass flow rate, $w \alpha$. 

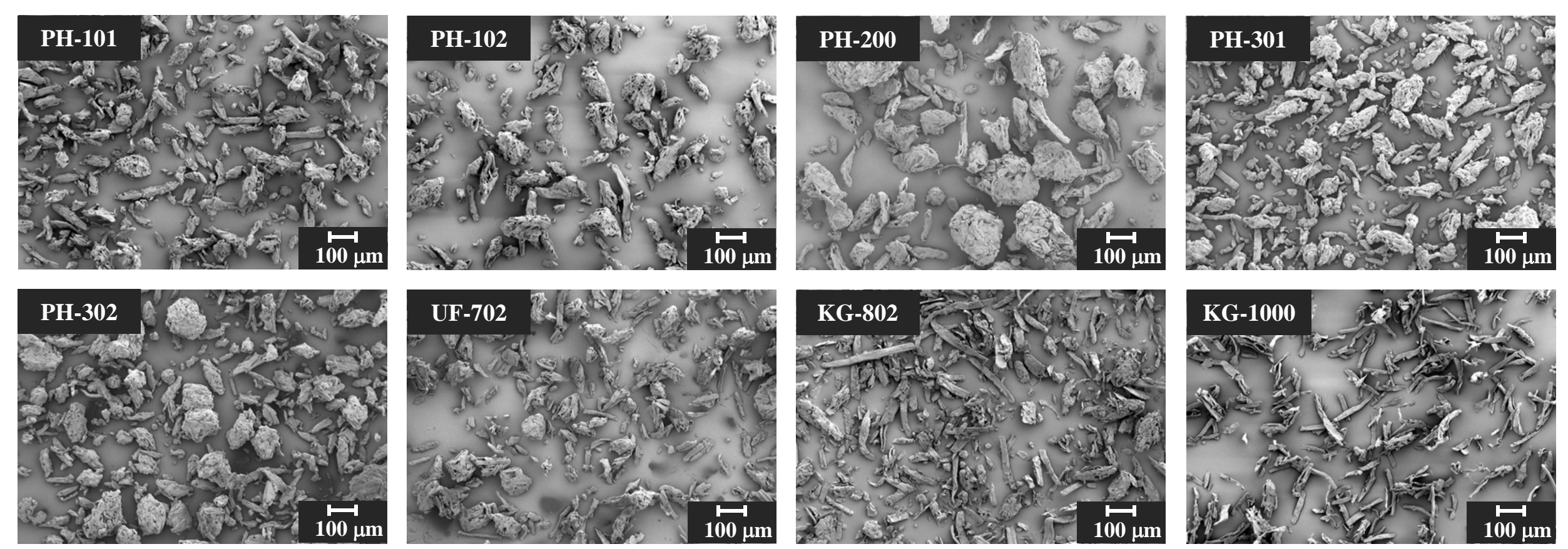

Fig. 1. SEM images of the different types of MCC particles. 


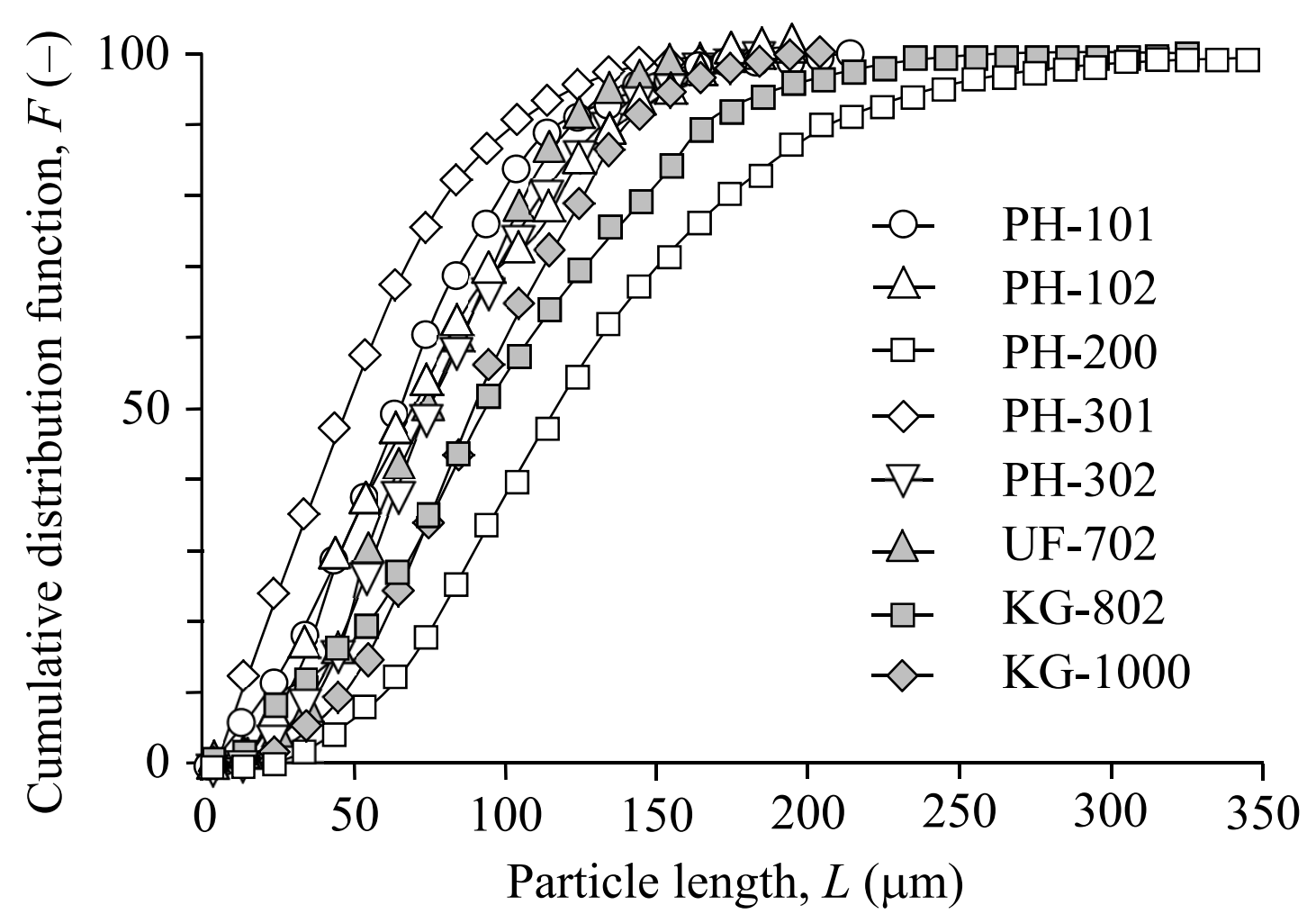

Fig. 2. Cumulative distribution functions, $F$, of the major axis lengths, $L$, of the MCC particles. 


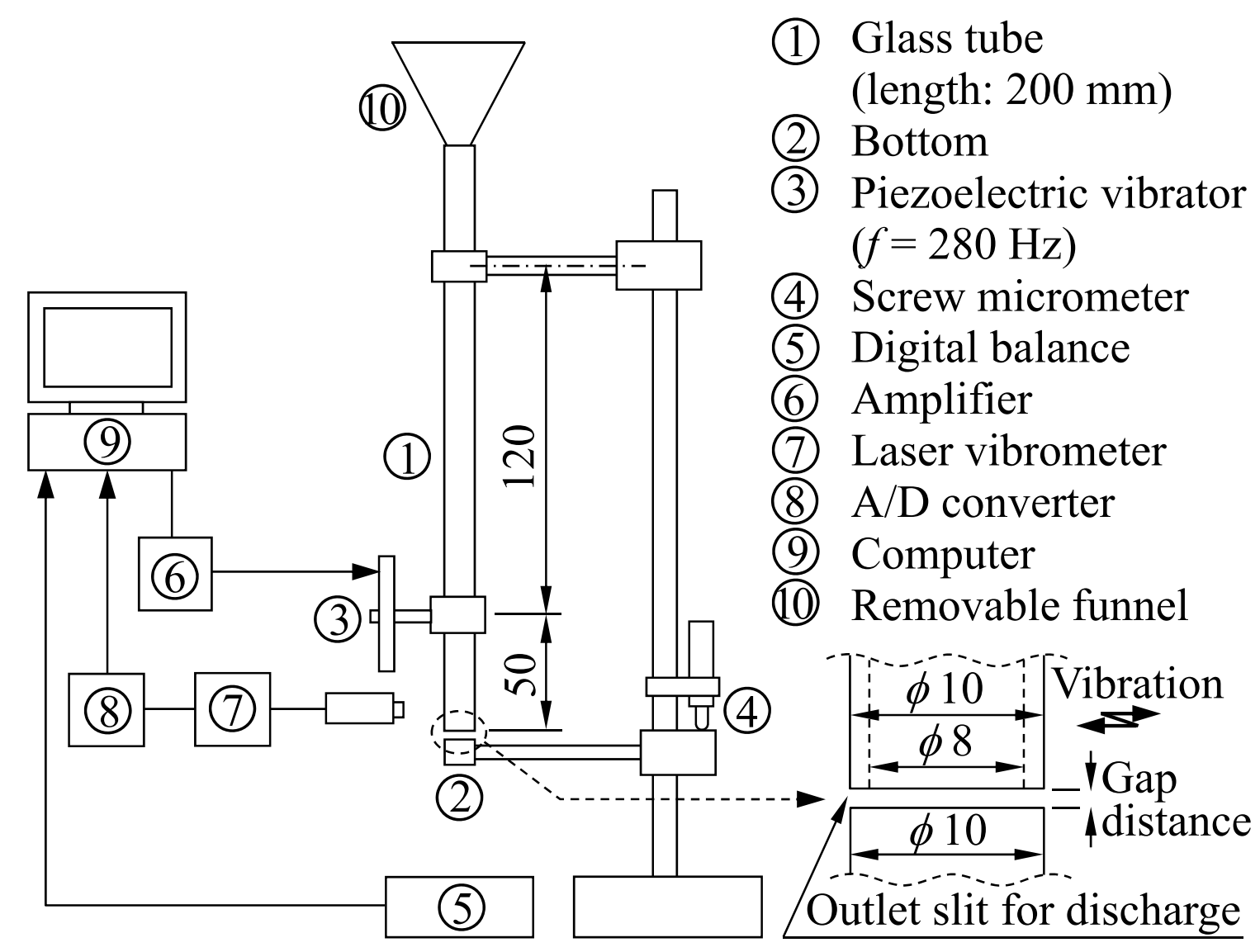

Fig. 3. Schematic diagram of the experimental setup. 


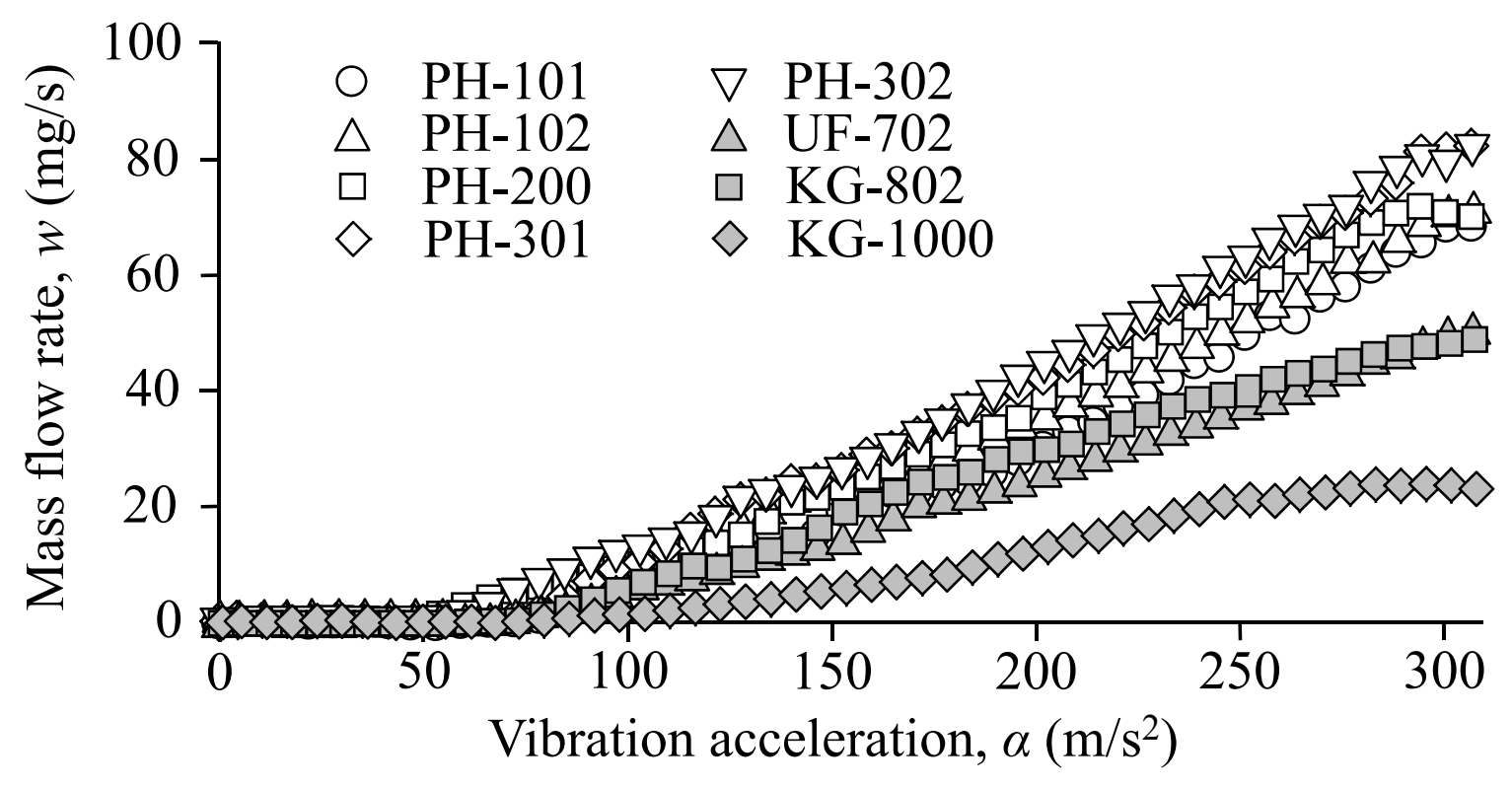

Fig. 4. Flowability profiles obtained using the vibration shear tube method. 


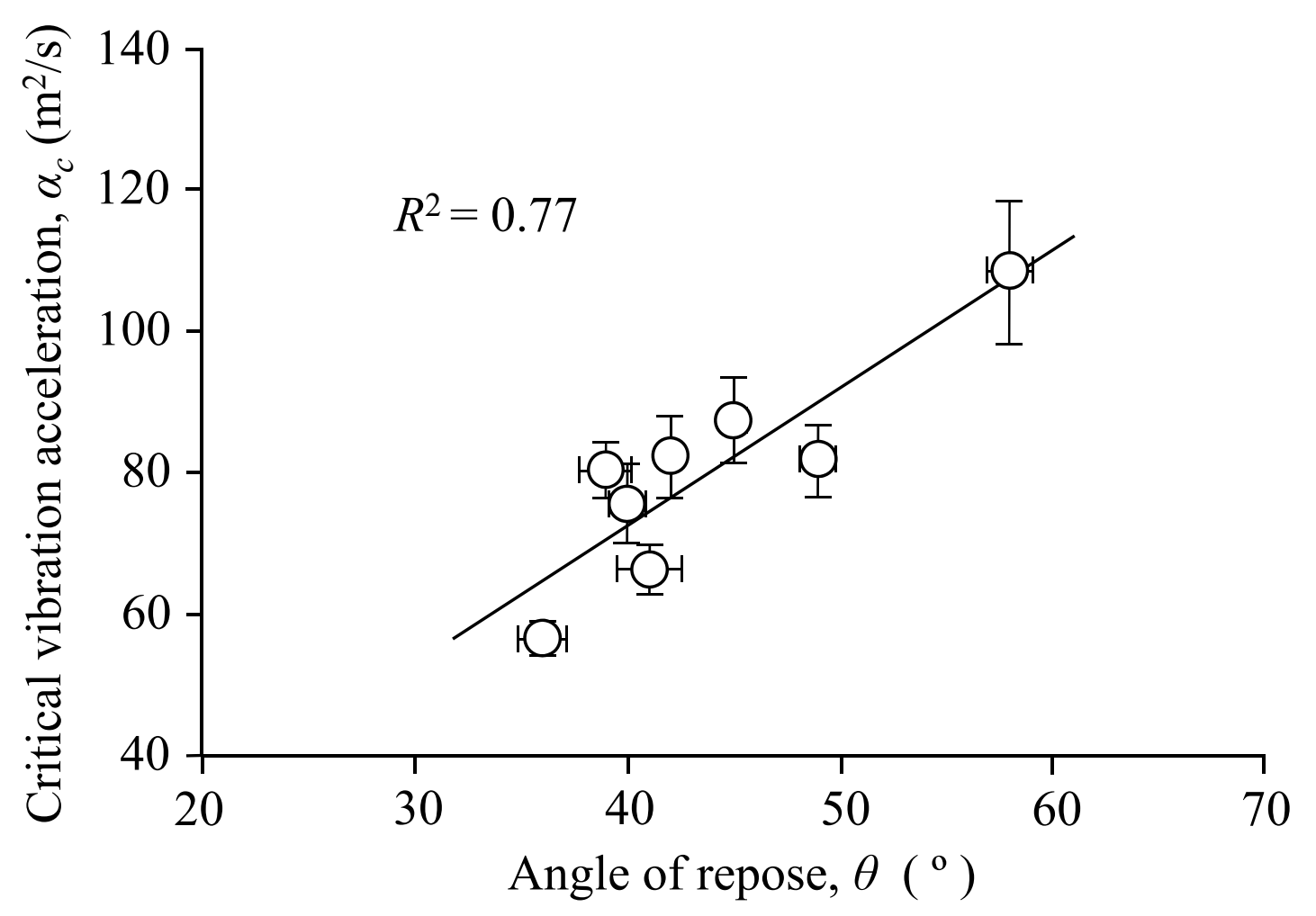

Fig. 5. Relationship between critical vibration acceleration, $\alpha_{c}$, and angle of repose, $\theta$. 


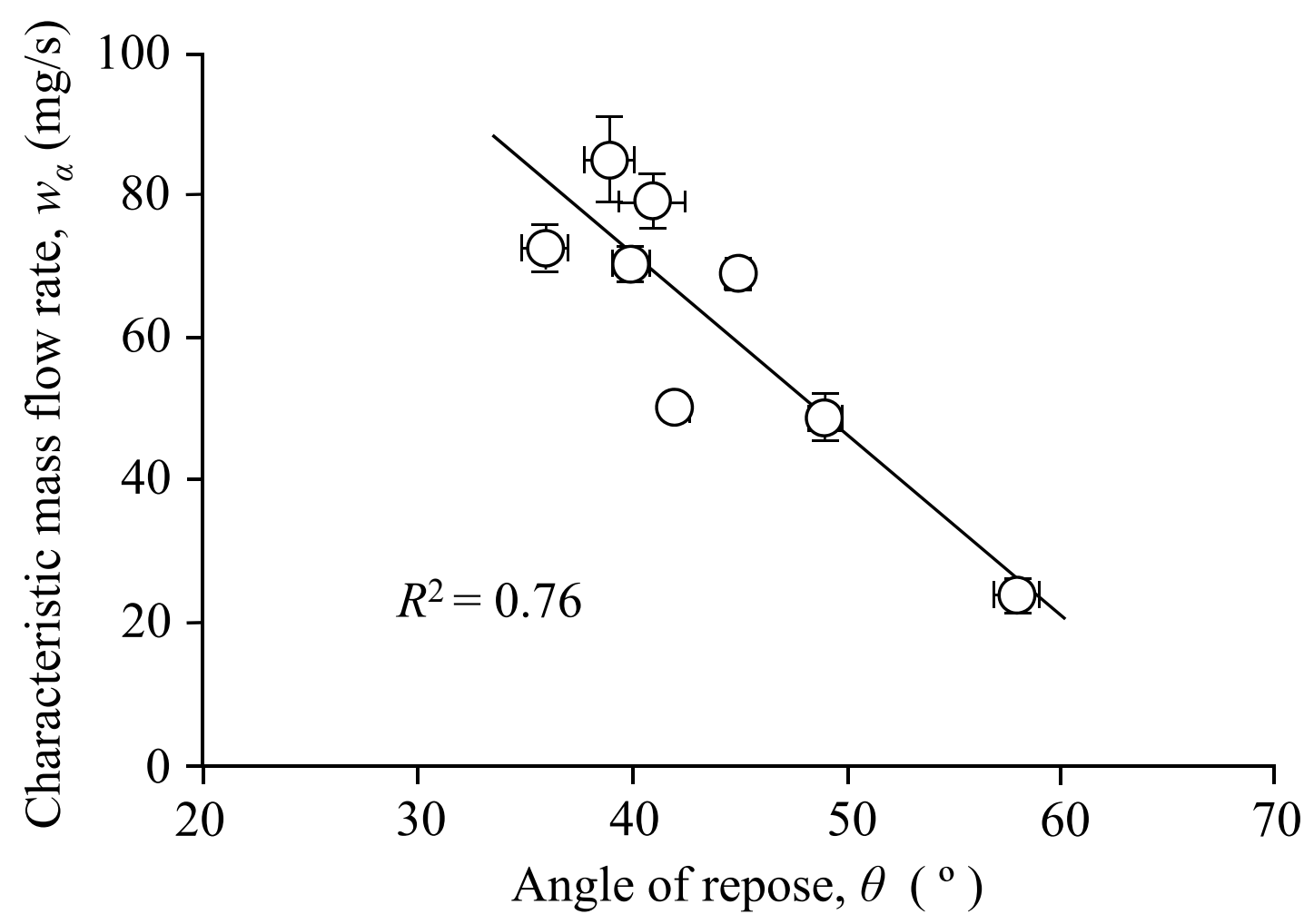

Fig. 6. Relationship between characteristic mass flow rate, $w_{\alpha}$, and angle of repose, $\theta$. 


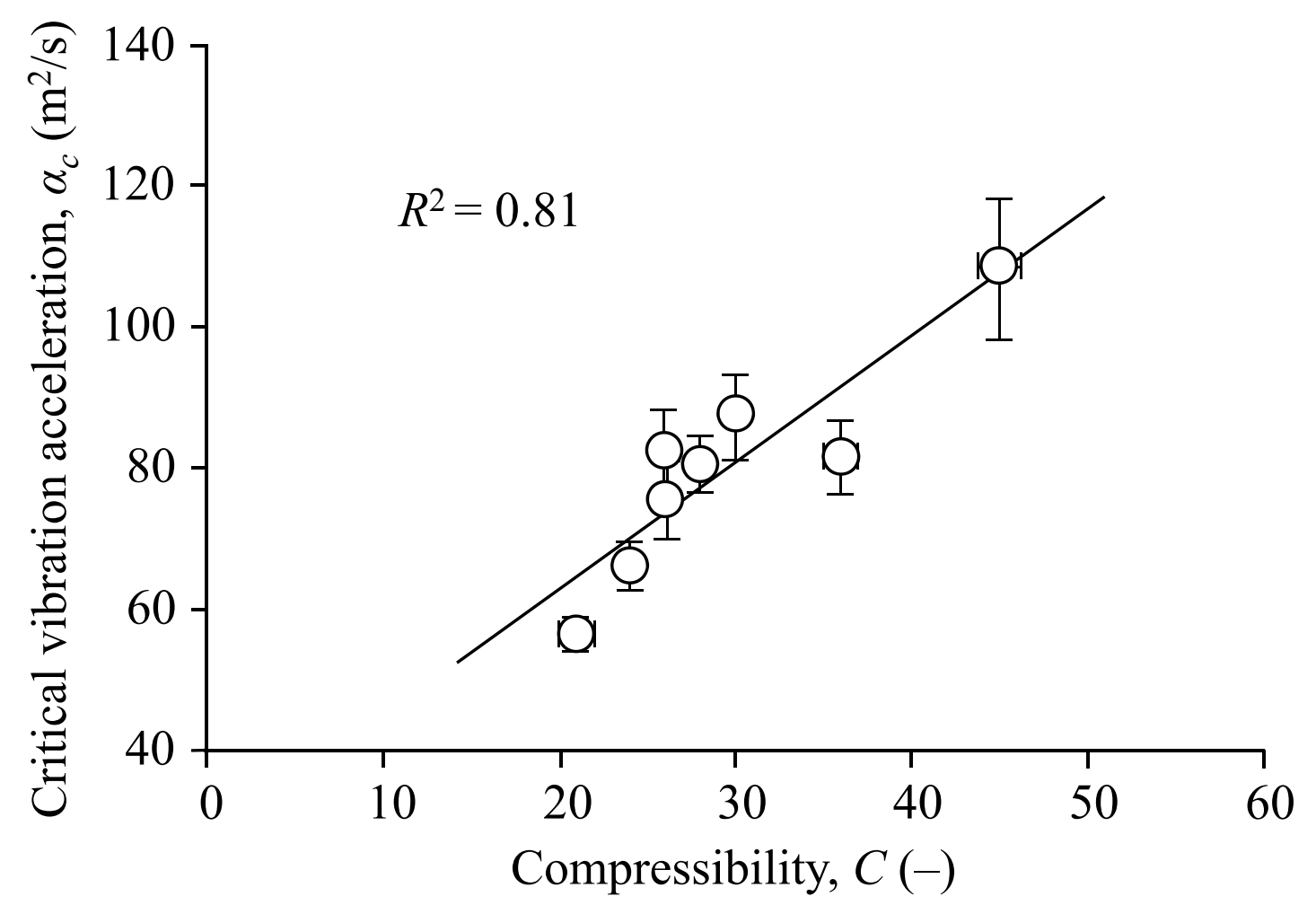

Fig. 7. Relationship between critical vibration acceleration, $\alpha_{c}$, and compressibility, $C$. 


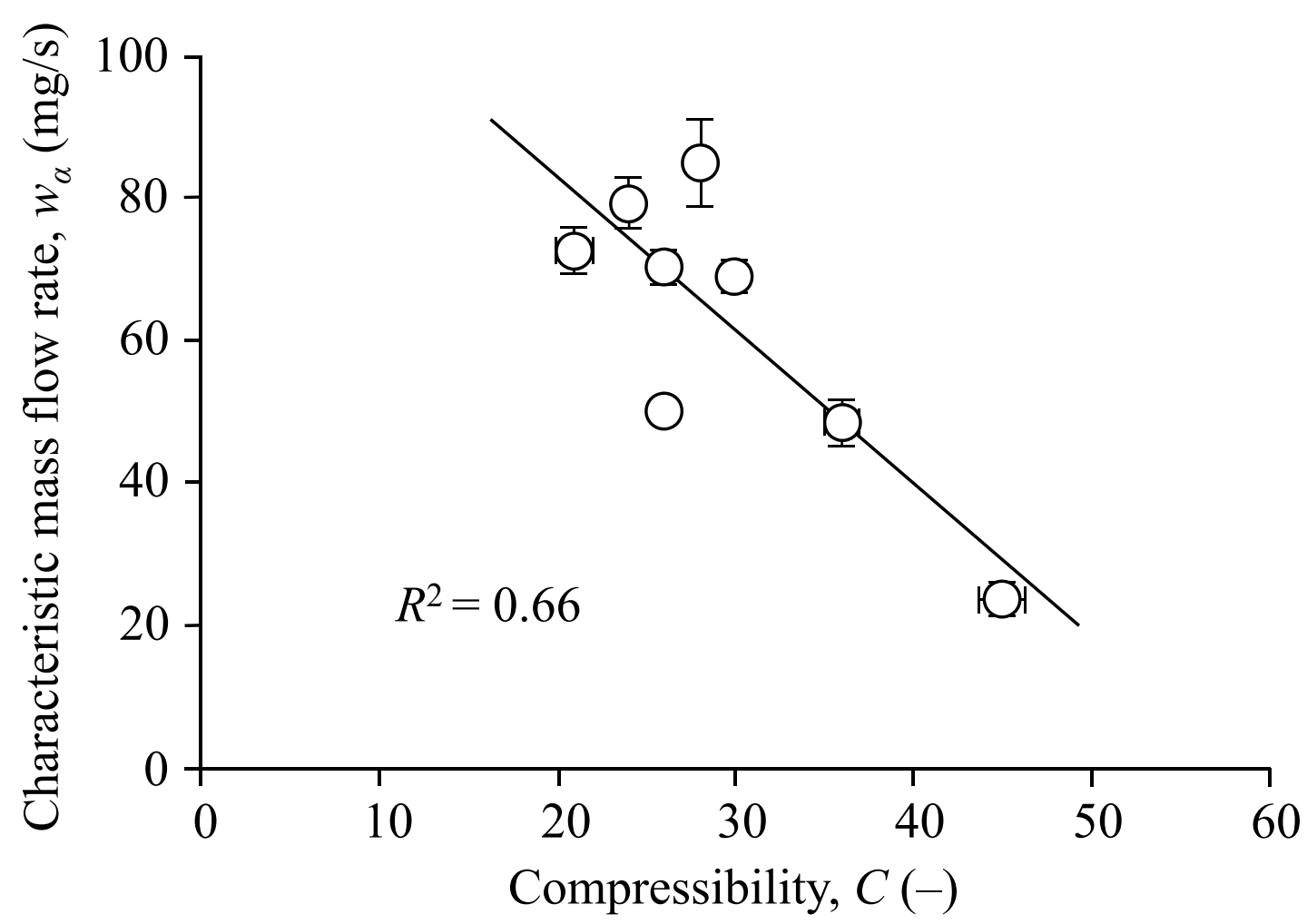

Fig. 8. Relationship between characteristic mass flow rate, $w_{\alpha}$, and compressibility, $C$. 


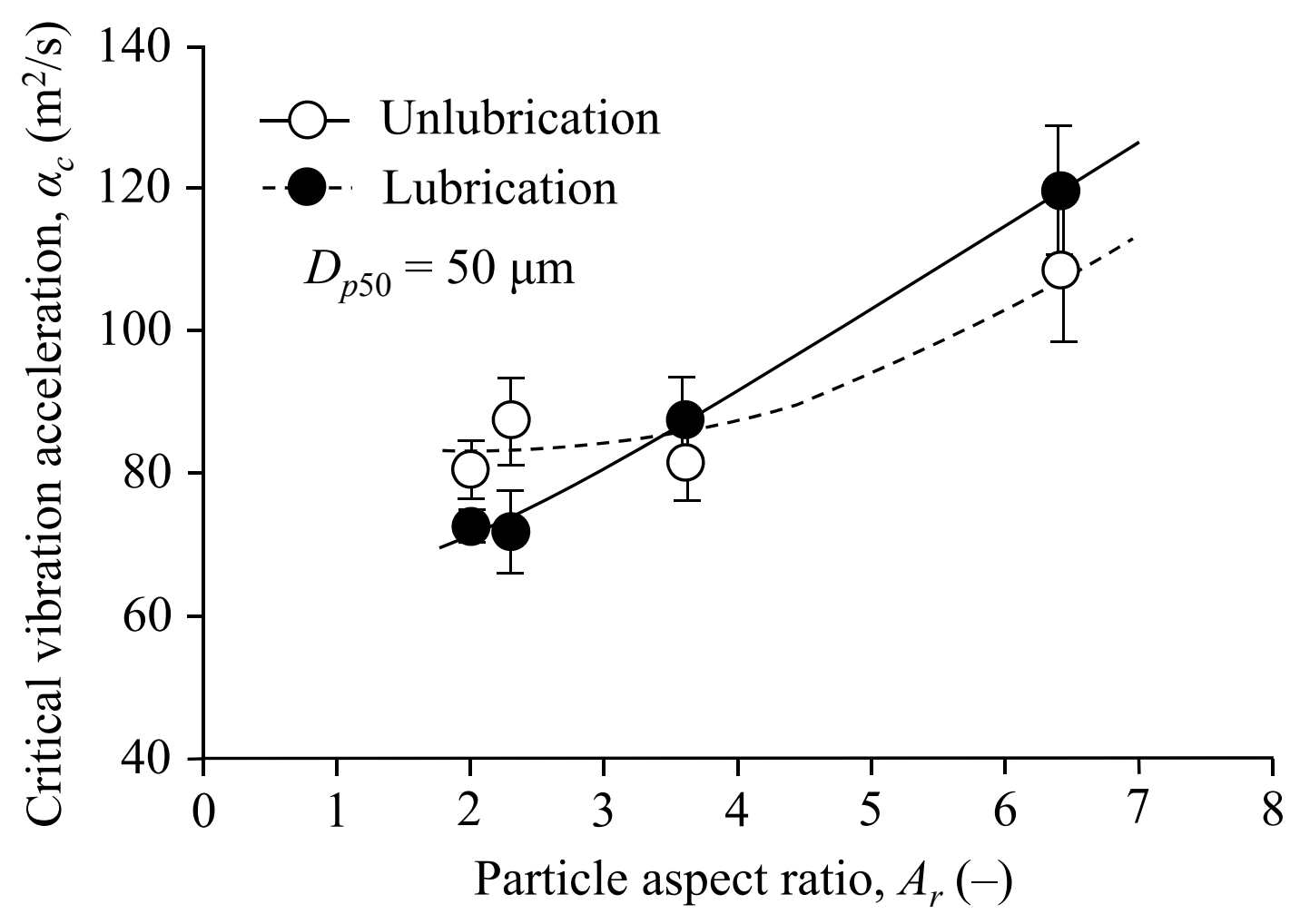

Fig. 9. Effects of particle aspect ratio, $A_{r}$, and surface modification on critical vibration acceleration, $\alpha_{c}$. 


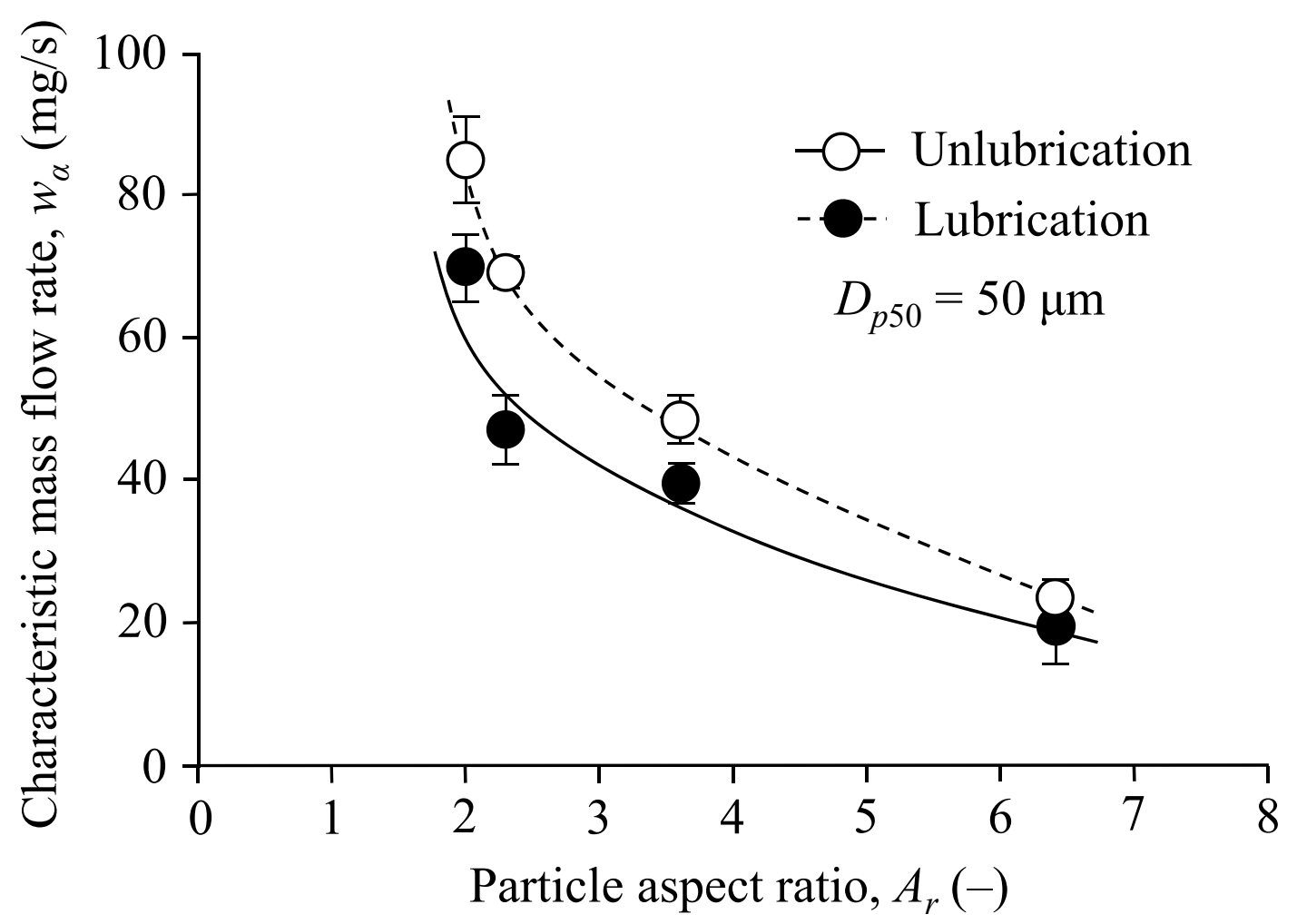

Fig. 10. Effects of particle aspect ratio, $A_{r}$, and surface modification on characteristic mass flow rate, $w_{\alpha}$. 